\title{
Risk Determinants of Acute Mountain Sickness in Trekkers in the Nepali Himalaya: a 24-Year Follow-Up
}

\author{
Marion McDevitt, DO, MPH; Scott E. McIntosh, MD, MPH; George Rodway, PhD, APRN; Jitsupa Peelay, MS; \\ Doug L. Adams, MStat; Bengt Kayser, MD, PhD \\ From the Division of Emergency Medicine (Drs McDevitt and McIntosh), the Department of Biomedical Informatics, School of Medicine (Ms \\ Peelay), and the School of Nursing (Mr Adams), University of Utah, Salt Lake City, UT, Division of Health Sciences, University of Nevada, Reno, \\ NV (Dr Rodway), and the Institute of Sports Sciences, and Department of Physiology, Faculty of Biology and Medicine, University of Lausanne, \\ Switzerland (Dr Kayser).
}

Objective.-Exposure to altitude may lead to acute mountain sickness (AMS) in nonacclimatized individuals. We surveyed AMS prevalence and potential risk factors in trekkers crossing a 5400-m pass in Nepal and compared the results with those of 2 similar studies conducted 12 and 24 years earlier.

Methods.-In April 2010, 500 surveys were distributed to English-speaking trekkers at $3500 \mathrm{~m}$ on their way to $5400 \mathrm{~m}$, of which $332(66 \%)$ surveys were returned complete. Acute mountain sickness was quantified with the Lake Louise Scoring System (LLSS, cutoff $\geq 3$ and $\geq 5$ ) and the Environmental Statistical Questionnaire III AMS-C score (ESQ-III, cutoff $\geq 0.7$ ). We surveyed demographics, body mass index (BMI), smoking habit, rate of ascent, awareness of AMS, and acetazolamide use.

Results.-Prevalence of AMS was 22\%, 23\%, and 48\% (ESQ-III $\geq 0.7$, LLSS $\geq 5$, and LLSS $\geq 3$, respectively) lower when compared with earlier studies. Risk factors for AMS were younger age, female sex, higher BMI, and smoking habit. Forty-two percent had elementary knowledge about the risk and prevention of AMS. Forty-four percent used acetazolamide. Trekkers took longer to climb from 3500 to $5400 \mathrm{~m}$ than in earlier studies.

Conclusions.-Prevalence of AMS continued to decline over a period of 24 years, likely as a result of slower ascent and increased use of acetazolamide. The AMS risk factors of younger age, female sex, and high BMI are consistent with prior studies. Awareness of risk and prevention of AMS remains low, indicating an opportunity to better educate trekkers and potentially further reduce AMS prevalence.

Key words: altitude, acute mountain sickness, Nepal, prevalence, tourism, trekking

\section{Introduction}

Acute mountain sickness (AMS) is a common form of high altitude illness that can develop in nonacclimatized persons shortly after ascent to high altitude $(>2500 \mathrm{~m})$. Acute mountain sickness is defined as the presence of headache appearing within a few hours upon ascent to altitude, accompanied by 1 or more of the following symptoms: loss of appetite, nausea, vomiting, weakness, lassitude, dizziness, and difficulty sleeping. ${ }^{1,2}$ It is generally self-limiting, resolving over the course of several days, but may progress to life-threatening high altitude cerebral edema (HACE). ${ }^{3}$ Risk factors for AMS include rate of ascent, altitude reached, sleeping altitude, and individual susceptibility. ${ }^{2-4}$

Corresponding author: Marion McDevitt, DO, Division of Emergency Medicine, University of Utah, 30 North 1900 East, Room 1C26, Salt Lake City, UT 84132 (e-mail: marion.mcdevitt@hsc.utah.edu).
The Himalaya attracts trekkers from all over the world. Since Nepal opened its borders to tourists in the mid-1900s, it has become a popular trekking and climbing destination. Significant morbidity and mortality attributable to altitude illness was subsequently reported. ${ }^{5}$ In response to these troubling observations, a Nepali nonprofit organization, the Himalayan Rescue Association (HRA), was formed in 1973. The HRA set up a health post in Pheriche (approximately $4300 \mathrm{~m}$ ) to educate trekkers, climbers, and porters on their way to Mt Everest base camp, and to treat those afflicted by altitude illness. Inspired by the subsequent decrease in altitude illness prevalence in Pheriche, ${ }^{6}$ the HRA established a second health post. In 1981 the Manang Health Post was established $(3500 \mathrm{~m})$, en route to Thorong-La, a 5400-m pass located midway on the popular Annapurna circuit trek. 
Since establishing this post, prevalence rates of altitude illness around the Thorong-La have decreased. A study by Gaillard et $\mathrm{al}^{7}$ reported that from 1986 to 1998 AMS prevalence dropped from $43 \%$ to $29 \%$ and explained this finding by slower ascent rates, better knowledge of AMS risk factors, and increased use of prophylactic medication. One medication being used as a prophylactic medication for the prevention of AMS is acetazolamide, a sulfonamide medication that inhibits carbonic anhydrase. We hypothesized that in 2010 AMS prevalence would have further decreased and that this reduction would be related to increased awareness of AMS and use of prophylactic medication. The aims of our study were therefore to assess in trekkers 1) the prevalence of AMS around the Thorong-La, 2) awareness regarding altitude illness, 3) risk factors for AMS, and 4) prophylactic medication use. Additionally, we sought to compare the results with those obtained 12 and 24 years earlier.,

\section{Methods}

In April 2010, English-language questionnaires were distributed to 500 adult trekkers who intended to trek over Thorong-La on the Annapurna circuit (Figure 1). April was selected because large numbers of trekkers typically complete the Annapurna circuit during this month. Surveys were distributed in Manang to be returned in Muktinath or vice versa. Inclusion criteria were trekkers 18 years or older who were able to read and write in English. Trekkers could freely choose not to participate or to abandon participation at any time. Total count of trekkers registered in Manang during the survey period was obtained from the Annapurna Conservation Area Project (ACAP) checkpost in Manang.

The questionnaire consisted of 2 main parts. The first section asked age, nationality, sex, height and weight, previous altitude experience, rate of ascent, first aid supplies carried, knowledge of AMS, medications used and carried, and health history. This section was to be filled out in Manang (or Muktinath) on the evening before beginning the ascent to $5400 \mathrm{~m}$. In contrast to previous studies in Manang, ${ }^{7,8}$ which surveyed participants after they had attended an HRA briefing on high altitude illness, the part of the survey used in this study was conducted before the HRA briefing to assess trekkers' basal knowledge of AMS.

The second part of the questionnaire consisted of 2 separate self-administered AMS scoring questionnaires that were completed after traversing the Thorong-La. The Lake Louise Scoring System (LLSS) ${ }^{9}$ and the Environmental Statistical Questionnaire III (ESQ-III) $)^{10}$ were used. The LLSS self-score is a 5-item questionnaire, which is based on the most frequent symptoms of AMS (headache, gastrointestinal symptoms, fatigue or weakness, dizziness or lightheadedness, and difficulty sleeping). Each item is scored 0 (not present) through 3 (severe or incapacitating). Single item scores are added up, and the maximal score is 15 . A score of 3 or higher with the presence of headache is considered AMS. Some studies, including the predecessors of this study, used LLS $\geq 5$ as a measure of AMS. We therefore examined prevalence based on both criteria. The ESQ-III uses a more complex set of 67 symptoms. The subjects rate

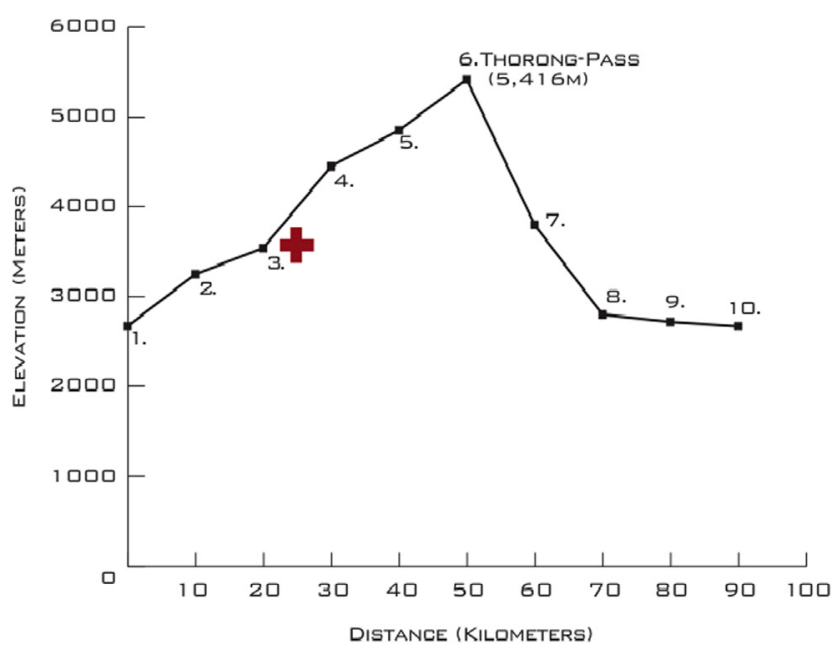

Figure 1. Thorong-La altitude profile showing typical route spending nights in each village marked (distance in kilometers, elevation in meters): 1. Chame (0 km, 2670 m); 2. Lower Pisang (19 km, 3250 m); 3. Manang (34 km, 3540 m); 4. Thorong Phedi (49 km, 4450 m); 5 . High Camp (50 km, $4850 \mathrm{~m})$; 6. Thorong La (55 km, $5416 \mathrm{~m}) ; 7$. Muktinath (65 km, $3800 \mathrm{~m}) ; 8$. Kagbeni (75 km,2800 m); 9 . Jomson (84 km, 2720 m); 10. Marpha $(90 \mathrm{~km}, 2670 \mathrm{~m})$. + indicates the Himalayan Rescue Association aid post in Manang. 
the severity of each symptom on a $0-5$ scale. Eleven AMS-associated scores are multiplied by a factorial weight, totaled, and adjusted to result in a compound cerebral AMS score (AMS-C). We used the recommended criterion threshold of an AMS-C score $\geq 0.7 .^{10}$

Using the same criteria as the 2 prior studies, ${ }^{7,8}$ we defined an "elementary awareness of AMS" if participants could identify 2 symptoms of AMS and list descent as a treatment.

Descriptive data analysis and logistic regression were performed using SPSS 19.0 (IBM, Somers, NY) to predict AMS from the variables age, sex, smoking, body mass index (BMI), acetazolamide use, and nationality as well as knowledge of AMS. Proportions were compared with the $\chi^{2}$ test. The University of Utah Institutional Review Board approved the study.

\section{Results}

The ACAP post in Manang reported that 2534 trekkers registered during April 2010. During that month, 862 trekkers attended the free HRA AMS lecture. This equates to $34 \%$ of the trekkers in the area. The majority (78\%) of our respondents attended the HRA lecture. Of the 500 questionnaires distributed, $332(66 \%)$ were returned completed. Therefore, we sampled about $13 \%$ of those passing through Manang. There were no differences in participation rate or indexes of AMS between primary English speakers and those with English as a second language.

The age range of participants was 18 to 75 years with a mean of $35 \pm 12$ years. Forty-nine percent were male, $48 \%$ were from primary English-speaking countries (Figure 2), and $11 \%$ identified themselves as smokers. The BMI ranged from 13 to $33 \mathrm{~kg} / \mathrm{m}^{2}$ with a mean of $23 \pm 3 \mathrm{~kg} / \mathrm{m}^{2}$. Forty-four percent reported using acetazolamide during the trek over Thorong-La; 58\% of these people brought acetazolamide with them from their home country. For those using acetazolamide, $76 \%$ documented a dose of $125 \mathrm{mg}$ twice daily. Of those surveyed, $66 \%$ of respondents cited some sleep disturbance, $44 \%$ saw a physician before their trek, $7 \%$ of women used oral contraception, $9 \%$ took nonsteroidal anti-inflammatory drugs (NSAIDs), acetaminophen, and aspirin, and $1 \%$ used dexamethasone during their trek. Forty-two percent met our criteria of having an elementary awareness of AMS.

After reaching Manang, $83 \%$ of participants had similar trekking profiles (ie, 2 nights at an altitude of approximately $3500 \mathrm{~m}$ with 2 additional nights on the ascent to Thorong-La). Only $1 \%$ of those surveyed trekked in reverse, from Muktinath to Manang (Figure 1).
Prevalence of AMS was $48 \%$ by LLSS $\geq 3,23 \%$ by LLSS $\geq 5$, and $22 \%$ by AMS-C (ESQ-III) scoring. Using LLSS $\geq 3$, age (odds ratio [OR], 0.969; 95\% CI, 0.948 to $0.990 ; \mathrm{p}=.005$ ), female sex (OR, 1.732; 95\% CI, 1.042 to $2.878 ; \mathrm{p}=.034)$, smoking (OR, 2.531; 95\% CI, 1.141 to 5.612; $\mathrm{p}=.022)$, and BMI (OR, 1.156; $95 \% \mathrm{CI}, 1.043$ to $1.281 ; \mathrm{p}=.006)$ were significant predictors (Table). Using the LLSS $\geq 5$, only smoking (OR, 2.46; 95\% CI, 0.089 to $5.539 ; \mathrm{p}=.030)$ was identified as a significant predictor of AMS. For the AMS-C (ESQ-III) scoring method, age (OR, 0.95; 95\% CI, 0.920 to $0.982 ; \mathrm{p}=.002)$ and female sex $(\mathrm{OR}, 2.28$; $95 \% \mathrm{CI}, 1.187$ to $4.394 ; \mathrm{p}=.013$ ) were predictors of AMS (Figure 3).

\section{Discussion}

Prevalence of AMS has further decreased among trekkers traveling over a 5400-m pass in the Nepali Himalaya when compared with studies performed in the same location 12 and 24 years earlier. We found a prevalence of AMS (ESQ-III) of $22 \%$ compared with $29 \%$ in 1998 and $43 \%$ in $19866^{7,8,11}$ This decrease can be explained by the increase in the time spent by trekkers on their way to the Thorong-La, improving acclimatization, and an increased use of acetazolamide.

\section{ASCENT RATE}

In 1986, 66\% of trekkers spent only 1 night en route from Manang to the Thorong-La and crossed the next day. In 1998, 76\% of trekkers spent 2 nights between Manang and the Thorong-La. In the present study, $83 \%$ of trekkers spent at least 2 nights in Manang and 2 further nights en route to the pass before crossing the next day. These changes in trekker behavior are likely a result of the increase in lodging facilities above Manang in the last decades, allowing trekkers to better keep to a gradual ascent profile. The current Wilderness Medical Society recommendations state that above an altitude of $3000 \mathrm{~m}$, individuals should not increase their sleeping elevation by more than $500 \mathrm{~m}$ per day and should include a rest day (ie, no ascent to higher sleeping elevation) every 3 to 4 days. $^{12}$ The majority of participants surveyed in the 1986 and 1998 studies did not comply, whereas most in the present study did.

\section{SELF-MEDICATION}

More subjects going to high altitude are using acetazolamide for the prevention of AMS. Self-medication with acetazolamide in trekkers at the same site increased from only $1 \%$ in $1986^{8}$ to $12 \%$ in $1998 .^{7}$ In 2010 we found that $44 \%$ of our participants used acetazolamide, 


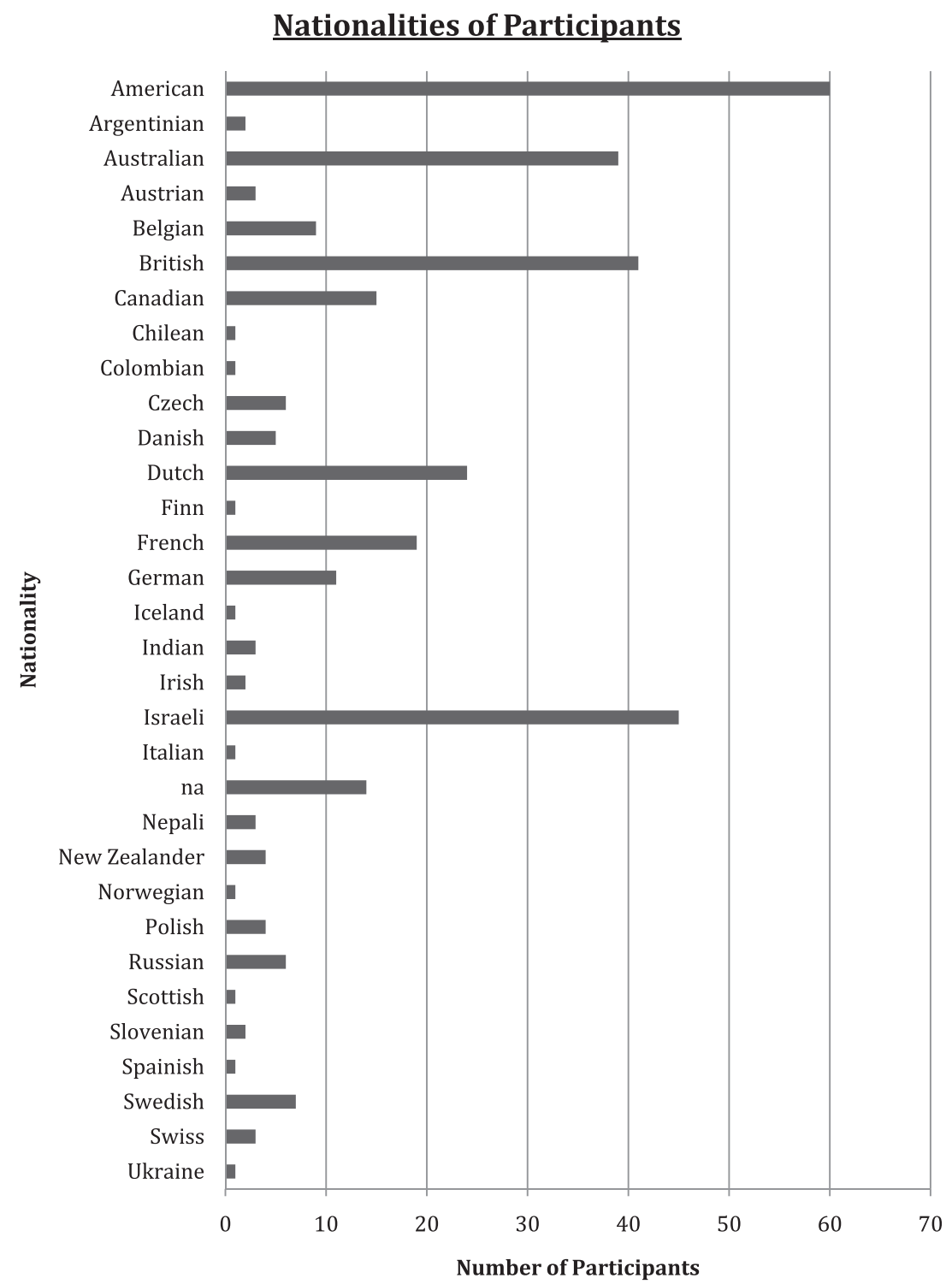

Figure 2. Nationalities of participants. NA, not answered on questionnaire.

Table. Logistic regression of variables for Lake Louise Scoring System (LLSS) using acute mountain sickness defined as LLSS $\geq 3$ and LLSS $\geq 5$, and the Environmental Statistical Questionnaire III

\begin{tabular}{|c|c|c|c|c|c|c|c|c|c|}
\hline \multirow[b]{3}{*}{ Variable } & \multicolumn{3}{|c|}{$L L S S \geq 3$} & \multicolumn{3}{|c|}{$L L S S \geq 5$} & \multicolumn{3}{|c|}{$E S Q-I I I$} \\
\hline & \multirow[b]{2}{*}{$O R$} & \multicolumn{2}{|c|}{$95 \% C I$} & \multirow[b]{2}{*}{$O R$} & \multicolumn{2}{|c|}{$95 \% \mathrm{CI}$} & \multirow[b]{2}{*}{$O R$} & \multicolumn{2}{|c|}{$95 \% \mathrm{CI}$} \\
\hline & & Lower & Upper & & Lower & Upper & & Lower & Upper \\
\hline Age & 0.969 & 0.948 & 0.99 & 1.004 & 0.98 & 1.029 & 0.951 & 0.92 & 0.982 \\
\hline Female & 1.732 & 1.042 & 2.878 & 1.579 & 0.879 & 2.836 & 2.284 & 1.187 & 4.394 \\
\hline Smoking & 2.531 & 1.141 & 5.612 & 2.456 & 1.089 & 5.539 & 0.854 & 0.332 & 2.198 \\
\hline BMI & 1.156 & 1.141 & 5.612 & 0.973 & 0.864 & 1.095 & 1 & 0.882 & 1.135 \\
\hline AMS awareness & 0.706 & 0.436 & 1.145 & 0.803 & 0.457 & 1.409 & 0.681 & 0.37 & 1.255 \\
\hline
\end{tabular}

AMS, acute mountain sickness; BMI, body mass index; ESQ-III, Environmental Statistical Questionnaire III; LLSS, Lake Louise Scoring System; OR, odds ratio. 


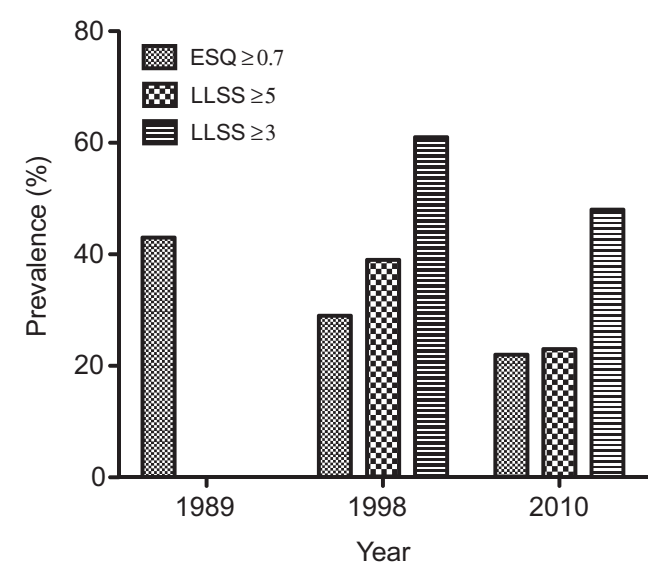

Figure 3. Prevalence of acute mountain sickness (AMS) from 3 studies over 24 years at $5400 \mathrm{~m}$ in Nepal. Questionnaires used were the Lake Louise Scoring System (LLSS), with scores of LLSS $\geq 3$ and LLSS $\geq 5$, and the Environmental Statistical Questionnaire III (ESQ-III).

indicating an important further increase. The dosage ranged from $125 \mathrm{mg}$ to $250 \mathrm{mg}$ twice daily. Although the efficacy and dosage of acetazolamide are still the subject of vivid debate, ${ }^{13-16}$ it can significantly reduce the risk of AMS and more so in high-risk settings. ${ }^{13}$ Our finding of reduced AMS prevalence is therefore likely to be explained in part by the important increase in acetazolamide use. The Wilderness Medical Society recommendations state that in low-risk situations, prophylactic medications are not necessary and individuals should rely on a gradual ascent profile if time allows. Prophylactic medications should be considered, in addition to gradual ascent, for use in moderate or high-risk situations. ${ }^{12}$ The rate of acetazolamide use in the present study suggests a tendency for exaggerated selfmedication because it is unlikely that all of our acetazolamide users were at high risk of AMS. However, we did not query why participants used acetazolamide (ie, prophylactic vs treatment). There are likely many factors for the declared increased use such as prescription by doctors; information from lectures, online sources, guidebooks, or peers; and fear of morbidity from altitude illness. Subedi et $\mathrm{al}^{17}$ found trekkers lack the understanding of AMS and any benefit of acetazolamide for its prevention and treatment. Fifty-eight percent of their respondents either believed or were unsure whether acetazolamide masked the early symptoms of AMS. ${ }^{17}$

The prevalence rates of AMS between those taking acetazolamide and those who did not were similar. Acetazolamide may have reduced symptoms of AMS, making a more sensitive population similar to a population not taking acetazolamide. Alternatively, acetazolamide may not have had much effect in this rather low-risk situation, or its side effects, similar to some of the symptoms of AMS, may have increased scores somewhat making them similar to those not taking the drug. Our findings should be taken cautiously as acetazolamide use was self-reported.

Only $9 \%$ of trekkers reported the use of an over-thecounter analgesic (eg, NSAIDs, acetaminophen, and aspirin) while at altitude. The fact that symptomatic treatment of altitude headache with over-the-counter analgesic has decreased (from $46 \%$ in $1998^{7}$ ) may be accounted for by the increase in acetazolamide use and its success in the prophylaxis or attenuation of AMS symptoms such as headache.

\section{AWARENESS}

The two previous studies reported trekkers' elementary awareness of AMS of $80 \%{ }^{8}$ and $95 \%$. $^{7}$ Our result of $42 \%$ is lower, likely because participants were asked about symptoms and treatments for AMS on arrival in Manang, before the HRA altitude illness lecture. Despite the Internet and increased ease of finding information about AMS, it is notable that fewer than half of the respondents had elementary knowledge of symptoms and treatment of AMS. This lack of knowledge suggests that the risks and dangers of high altitude travel might be further reduced with better pretravel preparation and education, and favors the continuation of the traditional lectures given at the HRA health posts in Manang and Pheriche. In 1999, Glazer et $\mathrm{al}^{18}$ stated that a "large population of at-risk high-altitude travelers may be relatively naïve to the dangers of altitude sickness." Our results suggest that this has not changed much in 2010, confirming similar results reported by Kilner and Mukerji. ${ }^{19}$ Physicians, travel companies, and other organizations that sponsor high altitude activities should emphasize pretravel preparation and education.

\section{PREVALENCE OF AMS}

When comparing the prevalence (ESQ-III AMS-C) of AMS during a 24-year span in the same location, we noticed a decline $(43 \%, 29 \%$, and $22 \%$ in 1986,1998 , and 2010, respectively). ${ }^{7,8}$ Using an LLSS cutoff score of $\geq 3$, during the last 12 years the prevalence of AMS also declined, from $61 \%$ to $48 \%$, in 1998 and 2010 , respectively. ${ }^{11}$ Using the LLSS, the presence of headache with a score of 3 or higher is considered AMS. ${ }^{9}$ As Dellasanta et $\mathrm{al}^{11}$ and Maggiorini et $\mathrm{al}^{20}$ showed, an LLSS score of $\geq 5$ correlates more closely with the ESQ-III AMS-C score. This is supported by our finding of $23 \%$ AMS using LLSS $\geq 5$ compared with $22 \%$ using the ESQ-III AMS-C score in the same population. 


\section{QUESTIONNAIRES FOR AMS}

Defining AMS in research terms remains a challenge, and the different scores developed are an attempt to define a purely clinical diagnosis in quantitative values. $^{21}$ The scoring systems used in our study rely on self-reported symptom intensity without a clinical examination component, which may increase diagnostic inaccuracy. Similar to Dellasanta et al, ${ }^{11}$ we noted a large difference in AMS diagnosis using the 2 scores when using the official LLSS cutoff $\geq 3$. Because the ESQ-III uses 67 symptom-based questions in English, an international population could interpret these questions variably. Dellasanta et $\mathrm{al}^{11}$ reported that the disagreement was not solely language-based but rather indicated that the 2 questionnaires identify slightly different populations, even in English speakers. In 1998, Maggiorini et $\mathrm{al}^{20}$ also compared the LLSS and ESQ-III AMS-C, but they included a clinical component. They postulated that the LLSS is a more effective selfassessment of AMS, but proposed to use a cutoff score at 5. We used both scoring systems, LLSS and ESQ-III, in an attempt to correlate results with the 2 prior studies by $\operatorname{Kayser}^{8}$ and by Gaillard et al. ${ }^{7}$ The original study ${ }^{8}$ was conducted before the creation of the LLSS. We again found the LLSS $\geq 3$ AMS prevalence to be close to double that of the ESQ-III, ${ }^{11}$ and when LLSS $\geq 5$ was used, it more closely matches that of the ESQ-III. Although LLSS is the current standard system used, ${ }^{20}$ there may still be a need to further define research cutoff scores for AMS. ${ }^{21}$

\section{AGE}

We found that age was inversely related to AMS. Younger age as a risk factor was reported before in other studies, ${ }^{7,8,22}$ but not all. ${ }^{23}$ Children may be at lower risk for AMS as compared with adults. ${ }^{24}$ However, children were excluded from our study to obtain a similar population as in the preceding 2 studies, in which the lowest ages were 17 and 18 years, respectively.

\section{SEX}

Inasmuch as we, as well as other studies, ${ }^{25,26}$ found that female sex appears to be a risk factor for AMS, one must ask whether women tend to report symptoms at a higher rate than men. The AMS questionnaires have not been specifically analyzed in terms of sex differences, but McIntyre et $\mathrm{al}^{27}$ found that "contrary to the common expectation that women report higher rates of morbidity... we found: no gender differences in the initial reporting of conditions." A recent comprehensive modeling study did not find any difference in prevalence of AMS between the sexes. ${ }^{28}$ Whether women are truly more at risk than men for AMS thus remains an open research question.

\section{BMI}

Obesity seems to be a risk factor for AMS. ${ }^{8,25,29-31} \mathrm{Ri}-\mathrm{Li}$ et $\mathrm{al}^{31}$ found that obese men have higher AMS scores than non-obese men during a 24-hour exposure to a simulated altitude of $3658 \mathrm{~m}$. Additionally, these obese men had lower arterial oxygen saturation values while sleeping than non-obese men, suggesting that impaired breathing during sleep may exacerbate exposure to hypoxia and thus lead to increased AMS in obese individuals. Sleep-associated breathing problems, such as nocturnal hypercapnia and hypoxia, are often obesityrelated respiratory changes that place these individuals at higher risk for altitude-related illness. ${ }^{31,32}$ Additionally, sleep disturbances are common at altitude, with a large number $(66 \%)$ of our respondents citing some sleep disturbance, possibly compounding the reported obesityrelated changes. Our finding of higher BMI as a risk factor for AMS appears to substantiate this theory.

\section{SMOKING}

Most epidemiological studies on AMS in trekkers and climbers have not found a correlation of smoking habits with AMS. ${ }^{7,8,23,33}$ The only study specifically designed to study smoking as a risk factor for AMS and long-term acclimatization reported that smoking slightly decreases the risk of AMS but impairs long-term altitude acclimatization and lung function during a prolonged stay at high altitude. ${ }^{34}$ A protective effect may be related to increased basal carbon monoxide levels, which is a function of smoking habits. ${ }^{35}$ Smoking is a risk factor for proteinuria, and Wada et $\mathrm{al}^{36}$ found increased proteinuria in $80 \%$ of their subjects with AMS. Our findings suggest that in trekkers around Thorong-La, smoking may be a risk factor for AMS. Because of the potential role of carbon monoxide in the control of breathing, vascular tone, neurotransmission, and cellular metabolism, smoking remains a habit that needs to be taken into account when studying AMS. ${ }^{34}$

\section{LIMITATIONS}

Because we did not capture the entire population that crossed the Thorong-La, our results may not be representative of this trekking group or trekkers as a whole. The number of trekkers registered at the Manang ACAP office may not be representative of the total attempting to cross the pass. Additionally, we do not know the number of people who attempted to cross the pass and did not succeed. The return rate of completed questionnaires 
(66\%) was comparable to that of the 2 previous studies (71\% and 53\% in 1986 and 1998, respectively) and rather common for this type of survey.

The questionnaires were written in English, a second language for approximately half of our respondents. The ESQ-III symptom-based questions may be difficult for foreign participants to accurately translate. Dellasanta et $\mathrm{al}^{11}$ found that using either scoring system in an international setting may pose problems for nonnative English speakers and might bias the results. Ideally, studies such as ours should be performed using questionnaires in the different native languages of the participants. The absence of differences in participation rate or indexes of AMS between native English speakers and other trekkers suggests that this was not a problem. In assessing awareness of AMS, we surveyed participants before the HRA AMS lecture in an attempt to discern their baseline awareness. Caution is warranted associating the decrease in awareness with the decreased prevalence, as in the present study $78 \%$ of participants listened to a lecture on AMS and were then exposed to the risk. Finally, AMS has nonspecific symptoms that overlap with dehydration, hyponatremia, and the side effects of acetazolamide; therefore, the prevalence data may thus be slightly exaggerated.

\section{Conclusions}

In unacclimatized subjects, AMS may lead to significant morbidity for trekkers in the high mountains. We found age, female sex, smoking, and BMI to be individual associated risk factors for the development of AMS. The prevalence of AMS in trekkers in Nepal has decreased in the last 24 years even though trekker awareness of AMS remains low. The drop in prevalence is likely the result of better facilities for overnight stays at altitude allowing slower ascent profiles and increased time for acclimatization as well as an increased prophylactic use of acetazolamide.

\section{Acknowledgments}

This study was conducted with support from the Himalayan Rescue Association and the Division of Emergency Medicine, University of Utah. The authors give special thanks to Michaela Black, RN, for data collection and Daren Mahoney for data entry.

\section{References}

1. Imray C, Wright A, Subudhi A, Roach R. Acute mountain sickness: pathophysiology, prevention, and treatment. Prog Cardiovasc Dis. 2010;52:467-484.
2. Barry PW, Pollard AJ. Altitude illness. BMJ. 2003;326: 915-919.

3. Hackett PH, Roach RC. High-altitude illness. $N$ Engl J Med. 2001;345:107-114.

4. Basnyat B, Murdoch DR. High-altitude illness. Lancet. 2003;361:1967-1974.

5. Hackett PH, Rennie D, Levine HD. The incidence, importance, and prophylaxis of acute mountain sickness. Lancet. 1976;2:1149-1155.

6. Hackett PH, Rennie D. Rales, peripheral edema, retinal hemorrhage and acute mountain sickness. Am J Med. 1979;67:214-218.

7. Gaillard S, Dellasanta P, Loutan L, Kayser B. Awareness, prevalence, medication use, and risk factors of acute mountain sickness in tourists trekking around the Annapurnas in Nepal: a 12-year follow-up. High Alt Med Biol. 2004:5:410-419.

8. Kayser B. Acute mountain sickness in western tourists around the Thorong Pass $(5400 \mathrm{~m})$ in Nepal. $J$ Wilderness Med. 1991;2:110-117.

9. Roach RC, Bärtsch P, Oelz O, Hackett PH. The Lake Louise acute mountain sickness scoring system. In: Sutton JR, Houston CS, Coates G, eds. Hypoxia and Molecular Medicine. Burlington, VT: Queen City Press; 1993: 272-274.

10. Sampson JB, Kobrick JL. The Environmental Symptoms Questionnaire: revisions and new field data. Aviat Space Envir Med. 1980;51:872-877.

11. Dellasanta P, Gaillard S, Loutan L, Kayser B. Comparing questionnaires for the assessment of acute mountain sickness. High Alt Med Biol. 2007;8:184-191.

12. Luks AM, McIntosh SE, Grissom CK, et al. Wilderness Medical Society. Wilderness Medical Society consensus guidelines for the prevention and treatment of acute altitude illness. Wilderness Environ Med. 2010;21:146-155.

13. Kayser B, Dumont L, Lysakowski C, Combescure C, Haller G, Tramèr MR. Reappraisal of acetazolamide for the prevention of acute mountain sickness: a systematic review and meta-analysis. High Alt Med Biol. 2012;13:82-92.

14. Low EV, Avery AJ, Gupta V, Schedlbauer A, Grocott MP. Identifying the lowest effective dose of acetazolamide for the prophylaxis of acute mountain sickness: systematic review and meta-analysis. BMJ. 2012;345:e6779.

15. Ritchie ND, Baggott AV, Todd WTA. Acetazolamide for the prevention of acute mountain sickness - a systematic review and meta-analysis. J Travel Med. 2012;19:298-307.

16. Dumont L, Mardirosoff C, Tramèr MR. Efficacy and harm of pharmacological prevention of acute mountain sickness: quantitative systematic review. BMJ. 2000;321: 267-272.

17. Subedi D, Marahatta R, Sharma S, Bajracharya R, Hillenbrand P, Soon Y. Trekkers' awareness of acute mountain sickness and acetazolamide. Wilderness Environ Med. 2008;19:321-322.

18. Glazer JL, Edgar C, Siegel MS. Awareness of altitude sickness among a sample of trekkers in Nepal. Wilderness Environ Med. 2005;16:132-138. 
19. Kilner T, Mukerji S. Acute mountain sickness prophylaxis: knowledge, attitudes, \& behaviours in the Everest region of Nepal. Travel Med Infect Dis. 2010;8:395-400.

20. Maggiorini M, Müller A, Hofstetter D, Bärtsch P, Oelz O. Assessment of acute mountain sickness by different score protocols in the Swiss Alps. Aviat Space Envir Med. 1998;69:1186-1192.

21. Roach R, Kayser B. Measuring mountain maladies. High Alt Med Biol. 2007;8:171-172.

22. Roach RC, Houston CS, Honigman B, et al. How well do older persons tolerate moderate altitude? West J Med. 1995;162:32-36.

23. Schneider M, Bernasch D, Weymann J, Holle R, Bartsch P. Acute mountain sickness: influence of susceptibility, preexposure, and ascent rate. Med Sci Sports Exerc. 2002;34:1886-1891.

24. Rexhaj E, Garcin S, Rimoldi SF, et al. Reproducibility of acute mountain sickness in children and adults: a prospective study. Pediatrics. 2011;127:e1445-1448.

25. Honigman B, Theis MK, Koziol-McLain J, et al. Acute mountain sickness in a general tourist population at moderate altitudes. Ann Intern Med. 1993;118:587-592.

26. Vann RD, Pollock NW, Pieper CF, et al. Statistical models of acute mountain sickness. High Alt Med Biol. 2005;6:32-42.

27. Macintyre S, Ford G, Hunt K. Do women 'over-report' morbidity? Men's and women's responses to structured prompting on a standard question on long standing illness. Soc Sci Med. 1999;48:89-98.
28. Beidleman BA, Tighiouart H, Schmid CS, Fulco CS, Muza SR. Predictive models of acute mountain sickness after rapid ascent to various altitudes. Med Sci Sports Exerc. 2013;45:792-800.

29. Hirata K, Masuyama S, Saito A. Obesity as risk factor for acute mountain sickness. Lancet. 1989;2:1040-1041.

30. Wu TY, Ding SQ, Liu JL, et al. Who should not go high: chronic disease and work at altitude during construction of the Qinghai-Tibet railroad. High Alt Med Biol. 2007;8:88-107.

31. Ri-Li G, Chase PJ, Witkowski S, et al. Obesity: associations with acute mountain sickness. Ann Intern Med. 2003;139:253-257.

32. Latshang TD, Bloch KE. How to treat patients with obstructive sleep apnea syndrome during an altitude sojourn. High Alt Med Biol. 2011;12:303-307.

33. Ziaee V, Yunesian M, Ahmadinejad Z, et al. Acute mountain sickness in Iranian trekkers around Mount Damavand (5671 m) in Iran. Wilderness Environ Med. 2003;14:214-219.

34. Wu TY, Ding SQ, Liu JL, et al. Smoking, acute mountain sickness and altitude acclimatisation: a cohort study. Thorax. 2012;67:914-919.

35. You H, Li X, Pei T, Huang Q, Liu F, Gao Y. Predictive value of basal exhaled nitric oxide and carbon monoxide for acute mountain sickness. Wilderness Environ Med. 2012;23:316-324.

36. Wada K, Mizuguchi Y, Wada Y, Ohno Y, Iino Y. Hyperlipidaemia, lack of sleep and smoking as risk factors for proteinuria among high altitude mountain trekkers. Nephrology. 2006;11:131-136. 